\title{
Electrical Tree Initiation in XLPE Cable Insulation under Constant DC, Grounded DC, and at Elevated Temperature
}

\author{
Ying Liu ${ }^{1}$, Xiaolong Cao ${ }^{1}$ and George Chen ${ }^{2}$ \\ ${ }^{1}$ State Key Laboratory of Electrical Insulation and Power Equipment \\ Xi'an Jiaotong University, Xi'an, 710049, China \\ ${ }^{2}$ Department of Electronics and Computer Science \\ University of Southampton, Southampton, SO17 1BJ, United Kingdom
}

\begin{abstract}
Electrical tree initiation behavior was investigated in XLPE insulation samples made from a HVDC cable by applying constant DC and grounded DC voltages under different temperatures. No trees appeared when a constant $D C$ voltage of $-60 \mathrm{kV}$ was applied for 12 days at room temperature or 20 days at $90{ }^{\circ} \mathrm{C}$, and the tree initiation time was estimated to be more than 200 days by Bayes statistical processing of zerofailure data. In the grounded DC voltage test, $-15 \mathrm{kV}$ prestress could trigger a tree, and under $-35 \mathrm{kV}$, the tree initiation rate reached $100 \%$. With the increase of DC prestress, both the initiation rate and tree length increased. Grounded DC trees were branch trees with dark-colored channels, and a similar material damage could be caused by the same DC prestress. The connection of a grounding resistor could reduce the damage of sample caused by the grounded DC voltage, and the tree initiation rate declined with the increase of the resistance. According to the experimental results, the tree initiation time under constant DC voltage was not significantly shortened at $90{ }^{\circ} \mathrm{C}$, whereas tree initiation under grounded DC voltage was promoted by the increase of temperature. From 25 to $70{ }^{\circ} \mathrm{C}$, the tree branches became longer and denser, and extended in more varied directions. The observations are explained by the injection, transfer, trapping and detrapping of space charges, and charge detrapping is believed to be the cause of material damage.
\end{abstract}

Index Terms - DC XLPE cable insulation, constant DC voltage, grounded DC tree, elevated temperature

\section{INTRODUCTION}

IN recent years, the increased renewable energy integration and international power trades have led to the global attention on high voltage direct current (HVDC) transmission systems. Because of the light weight, easy maintenance and environment friendliness, cross-linked polyethylene (XLPE) cable system has become a superior option for HVDC power transmission, and the ever-increasing operation voltage has made tree-like breakdown phenomenon in XLPE insulation a growing problem $[1,2]$.

The treeing characteristics have been investigated under DC voltage and various associated voltage waveforms [3-5]. Under the application of a continuously increasing DC voltage, the $50 \%$ tree initiation voltage was measured to be 30 and -35 $\mathrm{kV}$ for PE material by Noto [6], $-50 \mathrm{kV}$ for PMMA by Kitani [7], and 32 and $-33 \mathrm{kV}$ for XLPE by Sekii [8]. Apart from

Manuscript received on 16 October 2017, in final form 19 June 2018, accepted 8 July 2018. Corresponding author: Y. Liu. above, no records can be found of trees initiated under a constant DC voltage. In several researches about tree growth characteristics under DC voltage, the electrical trees were pretriggered by an AC or impulse voltage [9,10]. Recent investigations on tree initiation property of DC insulation were carried out by application of grounded DC voltage, polarity reversal voltage, impulses superimposed on the DC voltage, and impulses after DC prestress. It was believed that homo charges were injected into the sample under a high DC voltage, and their distribution around the needle weakened the concentrated electric field and prevented the formation of electrical trees. Under a sudden stimulus, these charges would be released and this caused tree initiation or even sample breakdown [4, 5, 8, 11-13].

Temperature is an important influencing factor for electrical treeing in solid insulation. In a research on AC trees, Chen found that from 50 to $90{ }^{\circ} \mathrm{C}$, the increase of test temperature reduced the time for tree initiation, and it could be attributed to the decrease of the threshold energy for damage and increase of the injection current [14]. In a study on periodically grounded DC tree from 20 to $80{ }^{\circ} \mathrm{C}$, Wang found that the 
initiation ratios, lengths, and widths of electrical trees were all increased with temperature due to the increased charge mobility under an elevated temperature [12].

In this paper, test specimens were made from XLPE insulation of a HVDC cable. The DC treeing test was performed at room temperature (RT) and $90{ }^{\circ} \mathrm{C}$, to find out if an elevated temperature will promote electrical tree initiation under a constant DC voltage. In addition, grounded DC treeing test was carried out under different prestress voltages, and grounding resistors were used to investigate its mitigation effect on the damage of XLPE samples caused by grounding. Grounded DC treeing test was also performed at different temperatures, including RT, 50 and $70{ }^{\circ} \mathrm{C}$, so as to study the influence of temperature on the grounded DC trees. Based on the experimental results, the relationships among the initiation rate and morphology of electrical trees and the DC prestress, grounding resistance as well as test temperature were established, and the failure mechanism of solid DC insulation was investigated.

\section{SAMPLE AND EXPERIMENTS}

\subsection{SAMPLE PREPARATION}

The test specimens were made from the XLPE insulation of a HVDC cable, which was the first one manufactured in China with the DC insulating and semiconducting materials imported from a European company. The XLPE insulation removed from this HVDC cable, with $0.3 \mathrm{~mm}$ thick inner semiconducting layer and $10 \mathrm{~mm}$ insulation, was cut into pieces of $5 \mathrm{~mm}$ thick, and after that, four sector specimens were made from one piece of such hollow disc, as illustrated in Figure 1.

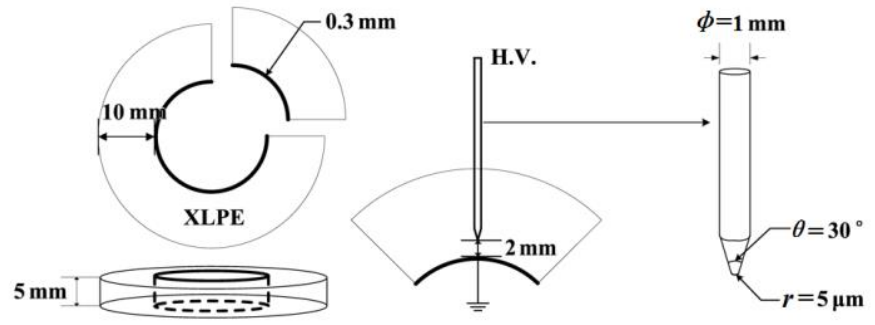

Figure 1. XLPE cable insulation specimen and needle-plane electrode. The characteristic parameters of the needle electrode are: trunk diameter $\phi=1 \mathrm{~mm}$, point angle $\theta=30^{\circ}$ and curvature radius of the tip $r=5 \mu \mathrm{m}$.

A steel needle, with a trunk of $1 \mathrm{~mm}$ in diameter and a tip of $(5 \pm 1) \mu \mathrm{m}$ in curvature radius and $30^{\circ}$ in pointed angle, was inserted into each specimen to serve as a high-voltage electrode. It was kept $(2 \pm 0.2) \mathrm{mm}$ away from the opposite electrode, i.e. the inner semi-conducting layer of the cable. Figure 1 shows the schematic diagrams and parameters of the specimen and electrodes used for the electrical treeing experiments. More details about the sample preparation and post-treatment can be found in [13].

\subsection{EXPERIMENTAL SYSTEM}

\subsubsection{CONSTANT DC VOLTAGE TEST}

Figure 2 shows the diagram of the experimental system for electrical treeing test under DC voltages and elevated temperatures up to $90^{\circ} \mathrm{C}$.

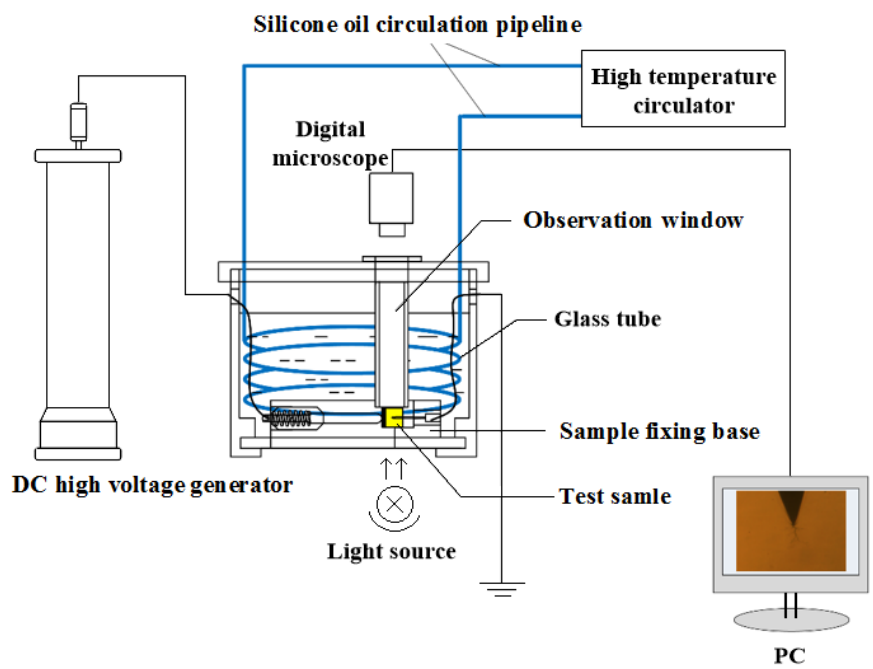

Figure 2. Diagram of the experimental system.

First of all, there was a sample fixing base for the sample to be mounted on. It not only helped to fix the sample position effectively, but also provided a convenient connection between the sample electrodes and the HV generator as well as the ground. This base was placed in a PTFE test container filled with silicone oil. The sample was immersed in silicone oil to prevent external discharges, to improve the transparency and to be heated up to the expected temperature.

The test voltage was supplied by a DC HV generator, which could provide a negative DC voltage up to $190 \mathrm{kV}$ at a rising or declining rate of $1 \mathrm{kV} / \mathrm{s}$. A hollow cylinder was hung right above the sample, which served as the observation window for the observer to look through by a microscope. This could largely reduce the adverse effect of the sloshing silicone oil on the photograph, which was caused by the electrophoretic effect under DC voltages. The images of needle tip region could be recorded periodically by a real-time digital micro-imaging system, consisting of a microscope, a charge coupled device (CCD) camera, a cold light source and a personal computer (PC), and the whole process of electrical tree initiation and growth could be observed.

Temperature control and regulation were achieved by a high temperature circulator and a transparent glass tube which was wound spirally along the inner wall of the container. The heated silicone oil was transmitted from the circulator to the glass tube through the circulation pipeline to heat the sample in the container. The maximal temperature for the present arrangement can reach as high as $200{ }^{\circ} \mathrm{C}$.

Trial tests showed that in the constant DC voltage test, the maximum voltage which could be applied on samples without a flashover was $-70 \mathrm{kV}$ for hours or $-60 \mathrm{kV}$ for days. Besides, the appearance and weight of the samples were checked before and after the test. No obvious swelling had occurred for the XLPE samples immersed in the high temperature silicone oil.

\subsubsection{GROUNDED DC VOLTAGE TEST}

Most part of the experimental platform used in the grounded 
DC voltage test was the same as shown in Figure 2. The only difference was a grounding device, which was designed to ground the sample at preset time point and condition after it had been DC prestressed.

Figure 3 shows the grounding device. An AC electromagnet was used to control switch SB2 by the actuation of an armature, and the position of switch SB2 determined the state of the sample, either DC stressed or grounded. The switch SB2 was realized by an aluminum rod. One end of it was in a permanent connection with the needle electrode of the sample, and the other end was connected to DC generator or to $R_{\mathrm{d}}$, depending on the status of the armature. A connecting rod made of epoxy resin was applied to transfer the actuation of the armature to switch SB2. $R_{\mathrm{d}}$ was a grounding resistor whose resistance could be changed. All parts of the grounding device were immersed in silicone oil.

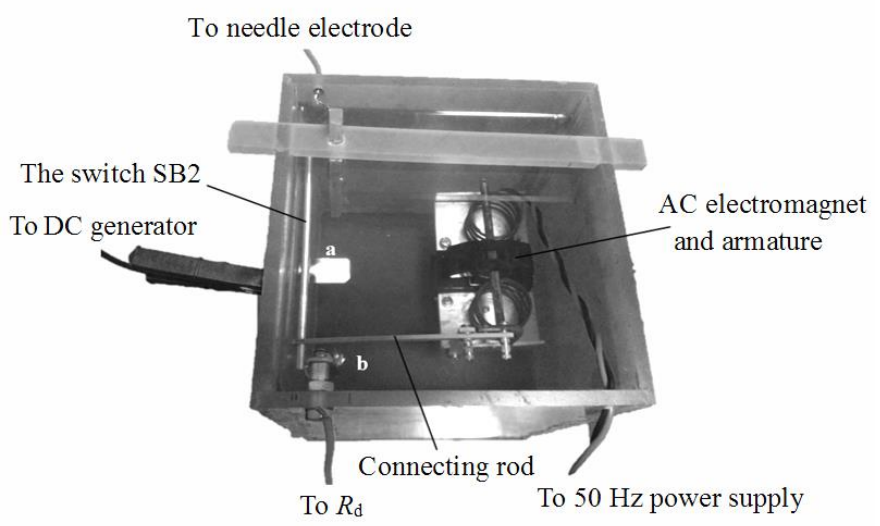

Figure 3. Photograph of the grounding device.

\subsection{EXPERIMENTAL PROCEDURE}

\subsubsection{CONSTANT DC VOLTAGE TEST}

At RT and $90{ }^{\circ} \mathrm{C}$, a DC voltage of $-60 \mathrm{kV}$ was applied on the sample for a preset length of time period. Then the power was turned off and the sample was observed by the microscope.

\subsubsection{GROUNDED DC VOLTAGE TEST}

In this part, the research was focused on the influence of DC prestress voltage, the grounding resistor, and the temperature on the electrical tree initiation characteristics of samples.

First of all, the influence of DC prestress voltage on the grounded tree initiation was studied. The tests were performed at RT with the resistor $R_{\mathrm{d}}$ removed from the grounding wire. At this condition, the sample could be regarded as directly grounded after it had been prestressed under different DC voltage for $10 \mathrm{~min}$. From -10 to $-35 \mathrm{kV}$, six groups of tests were carried out.

Then, the effect of grounding resistor was researched by using resistors of glass enamel film type with a resistance varying in the range of $10^{2}$ to $10^{5} \Omega$. The samples were grounded through different $R_{\mathrm{d}}$ after they had been prestressed by a DC voltage of $-35 \mathrm{kV}$ for $10 \mathrm{~min}$. The experiments were also performed at RT.

Presently the maximum long-term operating temperature permitted for commercial DC XLPE cables is $70{ }^{\circ} \mathrm{C}$, and the actual load rate normally does not exceed $70 \%$. Accordingly, in the study of temperature effect, three levels were chosen including 25 (RT), 50 and $70{ }^{\circ} \mathrm{C}$ to represent the insulation of a DC cable with zero load, normal load and full load. The samples were prestressed by a DC voltage of $-35 \mathrm{kV}$ for 10 min before they were grounded through a glass enamel film resistor of different resistance values.

In all the grounded DC voltage tests, the prestressing time duration of DC voltages was fixed to be $10 \mathrm{~min}$. Tanaka found that under a DC voltage, the amount of space charges injected into a sample would decrease continuously, and it took about 10 min for the space charges and electric field to reach stability between the pin and plane electrodes [15]. This conclusion was consistent with the experimental results of Ieda on PE material. He investigated the effect of DC prestressing duration on the length of short-circuit tree and voltage reversal tree, and found that the tree length increased until the duration reached $10 \mathrm{~min}$ and then slowly decreased [16]. In fact, the duration of $10 \mathrm{~min}$ had been adopted in our treeing test under DC prestress followed by impulse voltages, and it was proven to be valid [13].

After ten samples in each group had been tested, the number of samples with electrical trees was counted and the morphological characteristics of tree branches were recorded. In this paper, the tree initiation rate was the ratio of samples with trees to the total samples under test, and the tree length was defined as the distance between the needle tip and the distal branch of a tree along the electric field direction.

\section{EXPERIMENTAL RESULTS}

\subsection{TREE INITIATION UNDER CONSTANT DC VOLTAGES}

After a DC voltage of $-60 \mathrm{kV}$ had been constantly applied for a time period from 1 to 12 days at RT or from 1 to 20 days at $90{ }^{\circ} \mathrm{C}$, no trees could be found in any one of the samples, as shown in Table 1.

\begin{tabular}{cccc}
\multicolumn{4}{c}{ Table 1. Tree initiation data under constant $-60 \mathrm{kV}$ DC voltage. } \\
\hline $\begin{array}{c}\text { Temperature } \\
\left({ }^{\circ} \mathrm{C}\right)\end{array}$ & $\begin{array}{c}\text { Duration time } \\
(\text { day })\end{array}$ & $\begin{array}{c}\text { Sample } \\
\text { number }\end{array}$ & $\begin{array}{c}\text { Tree } \\
\text { number }\end{array}$ \\
\hline RT & 1 & 3 & 0 \\
& 2 & 2 & 0 \\
5 & 2 & 0 \\
7 & 1 & 0 \\
10 & 1 & 0 \\
12 & 1 & 0 \\
90 & 1 & 3 & 0 \\
& 2 & 2 & 0 \\
& 7 & 1 & 0 \\
& 10 & 2 & 0 \\
& 11 & 1 & 0 \\
20 & 1 & 0 \\
\hline
\end{tabular}

Compared to previous experimental results [13, 17], although the time has been extended to 20 days and the temperature increased to $90{ }^{\circ} \mathrm{C}$, there is still no trees triggered in the samples. This indicates the excellent withstand ability of the DC XLPE insulation to the constant DC voltages. 


\subsection{GROUNDED DC TREE INITIATION UNDER DIFFERENT PRESTRESS VOLTAGES}

\subsubsection{TREE INITIATION RATE}

The test results of tree initiation for samples directly grounded after prestressed by different DC voltages are listed in Table 2.

Table 2. Tree initiation data under different DC prestress voltages.

\begin{tabular}{cccc}
\hline $\begin{array}{c}\text { DC voltage } \\
(\mathrm{kV})\end{array}$ & $\begin{array}{c}\text { Tree initiation } \\
\text { rate }(\%)\end{array}$ & $\begin{array}{c}\text { Average tree } \\
\text { length }(\mu \mathrm{m})\end{array}$ & $\begin{array}{c}\text { Standard } \\
\text { deviation }(\mu \mathrm{m})\end{array}$ \\
\hline-10 & 0 & - & - \\
-15 & 20 & 5.55 & 1.91 \\
-20 & 60 & 26.43 & 6.73 \\
-25 & 70 & 26.04 & 8.08 \\
-30 & 90 & 43.68 & 14.33 \\
-35 & 100 & 65.81 & 30.90 \\
\hline
\end{tabular}

It can be seen from Table 2 that under $-10 \mathrm{kV}$, there is no tree triggered. Along with the rise of DC prestress voltage, the tree initiation rate increases. Under $-35 \mathrm{kV}$, trees appear in all 10 samples under test. Therefore, the tree initiation rate is $100 \%$ under $-35 \mathrm{kV}$ DC prestress.

\subsubsection{TREE LENGTH}

Besides the tree initiation rate, the average tree length also increases with the rise of DC voltage magnitude, as shown in Table 2. For a better observation of the whole dataset, the box chart of tree length data are presented in Figure 4. The relation between average tree length and DC prestress magnitude can be fitted by Equation (1):

$$
L=0.016 \times U^{2.335}
$$

where $L$ is the average tree length and $U$ is the magnitude of the DC prestress voltage.

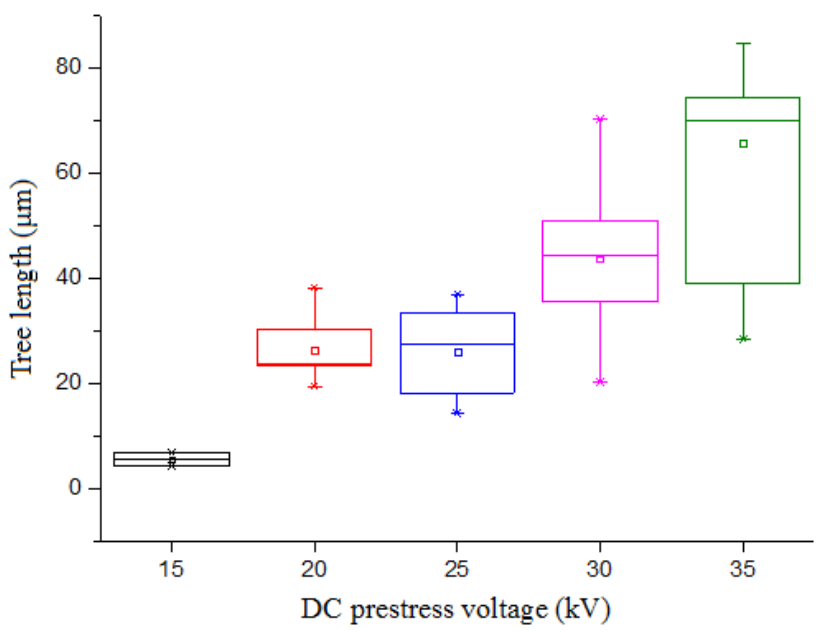

Figure 4. Relation between tree length and magnitude of DC prestress.

As shown in the rightmost column of Table 2, the standard deviation of tree length data is monotonically increasing with the rise of DC voltage, which can also be observed from Figure 4. A higher prestress voltage will bring in more energy stored around the tip of the needle. The sudden release of large amount of energy promotes the tree growth not only along the direction of electric field, but also towards other directions. This may be the reason for the increased dispersity of the tree length. More trees are initiated under higher DC prestress voltages, which can also have an impact on data dispersity.

\subsubsection{TREE SHAPES}

The shape of trees is observed as well. Under this experimental condition, electrical trees will be triggered immediately after the grounding of the needle. They are branch trees with dark-colored channels. If carefully distinguished, these branch trees can be further divided into three sub-groups, as shown in Figure 5.

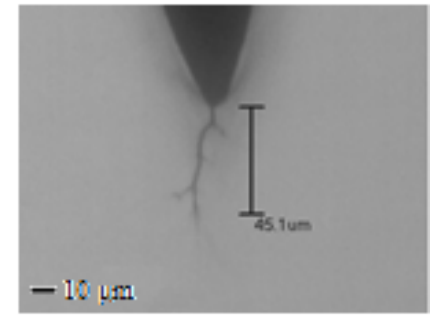

(a) One trunk

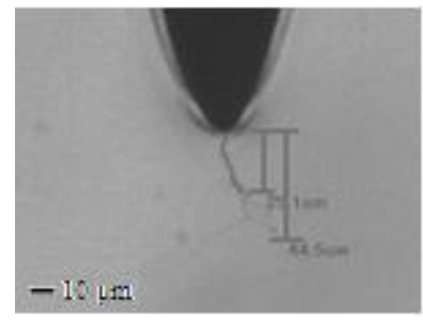

(b) One trunk with extended branches

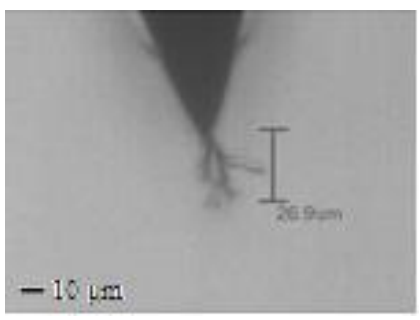

(c) Multi trunks

Figure 5. Photographs of the three kinds of electrical trees in samples directly grounded after DC prestress.

Most trees consist of a thick trunk, with or without extended branches at the end of the trunk, as shown in Figure 5a and 5b. Occasionally, the third kind of trees will appear, which are composed of several thick and short trunks, as shown in Figure 5c. Although the quantitative assessment is not possible because of limitations such as the resolution, a qualitative conclusion can be drawn for the electrical trees initiated under the same DC prestress. If the length of a tree is long, it will have few branches; if the channel of a tree is wide, it will be short; and vice versa. This indicates a similar treeing damage within the sample caused by the grounding impact of the needle electrode prestressed by the same DC voltage, although the tree shapes are not the same due to the influence of aggregation morphology of the material and microscopic defects around the needle tip.

\subsection{GROUNDED DC TREE INITIATION THROUGH DIFFERENT GROUNDING RESISTORS}

The resistors used in this experiment are RI80 series glass enamel film resistors. The influence of the resistance on the grounded DC tree characteristics was investigated.

\subsubsection{TREE INITIATION RATE}

The test results of tree initiation for samples grounded through different resistors after DC prestressed by $-35 \mathrm{kV}$ for $10 \mathrm{~min}$ are listed in Table 3 . The resistance of the glass enamel film resistors has an obvious effect on the grounded DC tree 
initiation rate. As shown in Table 3, the increase of the resistance from $250 \Omega$ to $100 \mathrm{k} \Omega$ leads to the decrease of the initiation rate from $100 \%$ to 0 .

Table 3. Grounded Tree initiation data through glass enamel film resistors with different resistance values.

\begin{tabular}{cccc}
\hline Resistance & $\begin{array}{c}\text { Tree initiation } \\
\text { rate }(\%)\end{array}$ & $\begin{array}{c}\text { Average tree } \\
\text { length }(\mu \mathrm{m})\end{array}$ & $\begin{array}{c}\text { Standard } \\
\text { deviation }(\mu \mathrm{m})\end{array}$ \\
\hline $250 \Omega$ & 100 & 90.78 & 18.36 \\
$1 \mathrm{k} \Omega$ & 80 & 54.60 & 10.24 \\
$10 \mathrm{k} \Omega$ & 50 & 57.96 & 18.99 \\
$100 \mathrm{k} \Omega$ & 0 & - & - \\
\hline
\end{tabular}

\subsubsection{TREE LENGTH}

As can be seen from Table 3, when the grounding resistance increases from $250 \Omega$ to $1 \mathrm{k} \Omega$, the tree length decreases obviously from 90.8 to $54.6 \mu \mathrm{m}$. When the resistance continues going up from 1 to $10 \mathrm{k} \Omega$, the tree length no longer changes significantly. The standard deviation of tree length data is about the same under the three resistance values.

\subsubsection{TREE SHAPES}

Figure 6 presents two photos of the trees triggered through a grounding resistor of $1 \mathrm{k} \Omega$. It can be seen that for the electrical trees triggered through grounding resistors, the color is lighter and the branch channels are much narrower compared to those trees triggered by direct grounding in Section 3.2. It seems that the glass enamel film resistor of a proper resistance can significantly reduce the damage of samples caused by grounding.

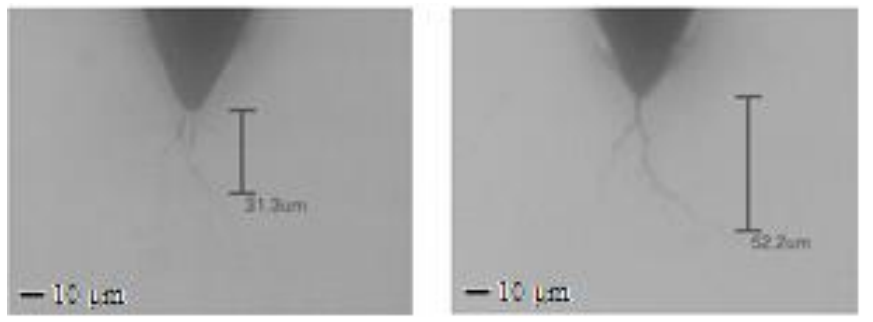

Figure 6. Photographs of the grounded DC trees triggered through a grounding resistor of $1 \mathrm{k} \Omega$.

\subsection{GROUNDED DC TREE INITIATION UNDER DIFFERENT TEMPERATURES}

\subsubsection{TREE INITIATION RATE}

Under the same DC prestress voltage of $-35 \mathrm{kV}$, the tree initiation rates under three temperature levels with different grounding resistance values are listed in Table 4. In order to investigate the influence of both temperature and grounding resistance on tree initiation rate, different range of grounding resistance was adopted at different temperature, with an aim to obtain the tree initiation rate from 0 to $100 \%$ at different conditions.

It can be seen that along with the rise of temperature, electrical trees can be initiated with a larger resistance. This indicates that an elevated temperature makes it easier for the trees to be triggered in the XLPE samples, which is consistent with the effect of temperature on the initiation characteristics of AC trees [14].
Table 4. Tree initiation rates under the three temperatures $(\%)$.

\begin{tabular}{cccc}
\hline \multirow{2}{*}{ Resistance } & \multicolumn{3}{c}{ Temperature $\left({ }^{\circ} \mathrm{C}\right)$} \\
\cline { 2 - 4 } & 25 & 50 & 70 \\
\hline $250 \Omega$ & 100 & - & - \\
$1 \mathrm{k} \Omega$ & 80 & 100 & - \\
$10 \mathrm{k} \Omega$ & 50 & 70 & 100 \\
$100 \mathrm{k} \Omega$ & 0 & 40 & 80 \\
$1 \mathrm{M} \Omega$ & - & 20 & 50 \\
$10 \mathrm{M} \Omega$ & - & 0 & 20 \\
$100 \mathrm{M} \Omega$ & - & - & 0 \\
\hline
\end{tabular}

\subsubsection{TREE LENGTH}

The relationship between the length of electrical trees and the resistance of grounding resistors is presented in Figure 7.

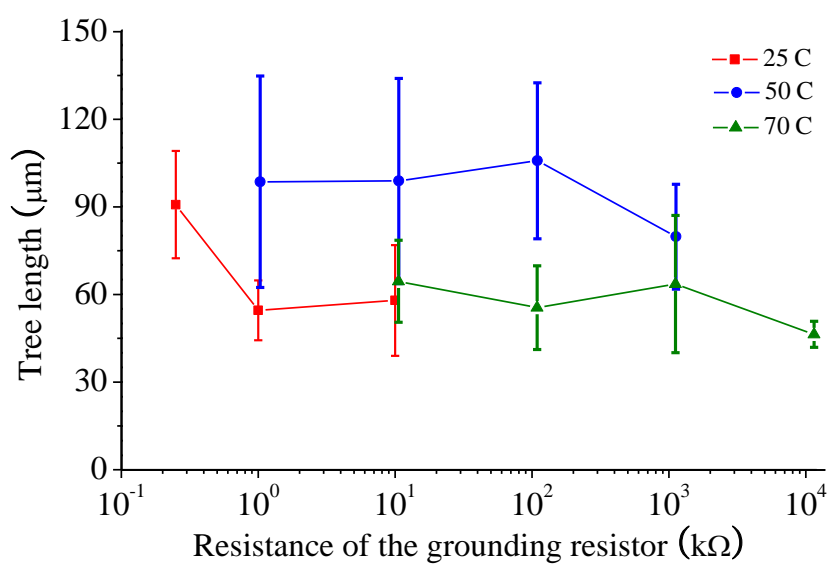

Figure 7. Relationship between the tree length and grounding resistance under different temperatures.

As can be seen from Figure 7 that under all temperature levels, with the increase of resistance the tree length shows a slight downward trend, which corresponds with the decrease of the tree initiation rate. It was also observed that the trees initiated at $50{ }^{\circ} \mathrm{C}$ have not only the longest branches but also the largest standard deviations among the three groups of trees initiated at RT, $50{ }^{\circ} \mathrm{C}$ and $70{ }^{\circ} \mathrm{C}$.

\subsubsection{TREE SHAPES}

Comparisons are made among the three groups of trees initiated under different temperatures, and some distinct morphological characters are found. Figure 8 gives some photos of the trees. For the sake of space limitation, only two trees at each temperature level are presented, corresponding to the minimum and maximum grounding resistance shown in Table 4. For example, Trees initiated through a resistor of 10 $\mathrm{k} \Omega$ and $10 \mathrm{M} \Omega$ are chosen for the group of $70{ }^{\circ} \mathrm{C}$.

As can be seen from Figure $8 \mathrm{a}$, the trees initiated at $25^{\circ} \mathrm{C}$ always start with a thick trunk at the needle tip which grows along the field direction, and then some thinner and lightercolored branches appear and extend in other directions. The trees mainly grow in longitudinal direction. Along with the increase of grounding resistance, the tree length becomes shorter, the branches become lighter in color, and the channels become narrower.

The trees initiated at $50{ }^{\circ} \mathrm{C}$ have long branches whose total lengths are close to each other. For most trees, there are more than one trunk. These trunks are similar in both width and 


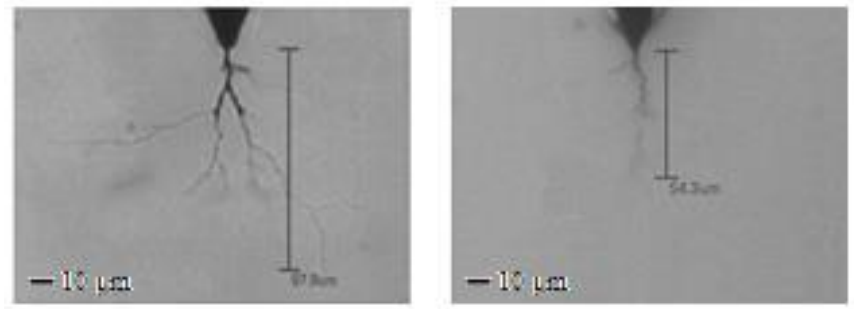

(a) Trees initiated at $25{ }^{\circ} \mathrm{C}$ through a resistor of $250 \Omega$ (left) and $10 \mathrm{k} \Omega$ (right)

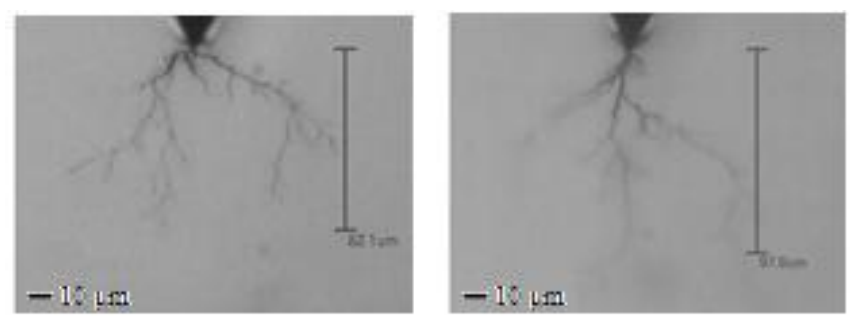

(b) Trees initiated at $50{ }^{\circ} \mathrm{C}$ through a resistor of $1 \mathrm{k} \Omega$ (left) and $1 \mathrm{M} \Omega$ (right)

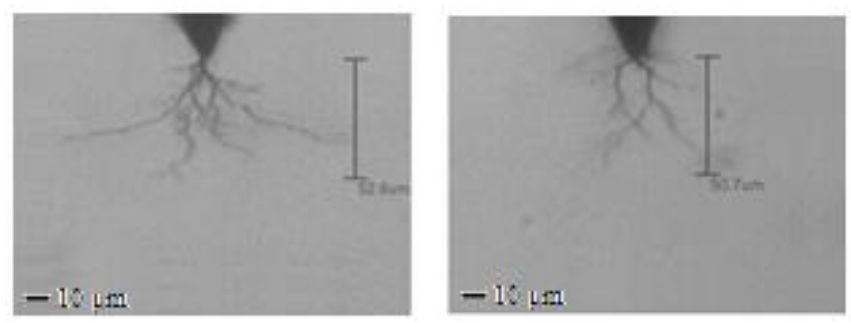

(c) Trees initiated at $70{ }^{\circ} \mathrm{C}$ through a resistor of $10 \mathrm{k} \Omega$ (left) and $10 \mathrm{M} \Omega$ (right) Figure 8. Photographs of the grounded DC trees under the three temperature levels through a grounding resistor of different resistance.

color, but rather scattered in location, with a lot of thin and light-colored branches extending from them. Trees mainly grow in the longitudinal direction, same as those at $25^{\circ} \mathrm{C}$.

For the trees initiated at $70{ }^{\circ} \mathrm{C}$, there are lots of branches instead of just a single trunk. These branches are densely located and extend towards varied directions, even showing a pronounced tendency to grow laterally. These are obviously different from the former two groups.

To sum up, at an elevated temperature, the trees will grow faster, the branches will become more densely distributed and have a higher tendency to grow in the direction perpendicular to the electric field.

\section{DISCUSSION}

\subsection{TREE INITIATION UNDER CONSTANT DC VOLTAGES}

Suppose the tree initiation time data fit the 2-parameter Weibull distribution, the expression for the cumulative density function can be described as [18]:

$$
F(t)=1-\exp \left[-\left(\frac{t}{\alpha}\right)^{\beta}\right]
$$

where $t$ is the tree initiation time, $\alpha$ is the scale parameter, $\beta$ is the shape parameter, and $F(t)$ is the probability of tree initiation at a time less than or equal to $t$.
Because no trees have been initiated under constant DC voltages, the tree initiation time should be regarded as zerofailure data. For the reliability analysis of zero-failure data, Bayes estimation method is widely applied, usually based on a priori distribution constructed by a subtraction function $[19$, 20]. Some details of the processing method are given below.

The samples are divided into $m$ groups. The test termination time of each group was set to be $t_{i}(i=1,2, \ldots, m)$ with $t_{1}<t_{2}<\cdots<t_{m}$. In group $i$, the number of samples tested is $n_{i}$. Accordingly, the zero-failure data are recorded as $\left(t_{i}, n_{i}\right)$.

By setting $P_{i}=P\left(t \leq t_{i}\right)=F\left(t_{i}\right)$ and choosing $P_{i-1}$, subtraction function of $P_{i}$, as the kernel of its prior density, the Bayes estimation of $P_{i}$ under the squared loss can be determined by Equation (3):

$$
\begin{gathered}
P_{i}=1-\frac{\left(s_{i}+3\right)\left[\left(1-P_{i-1}\right)^{s_{i}+4}-\left(1-\lambda_{i}\right)^{s_{i}+4}\right]}{\left(s_{i}+4\right)\left[\left(1-P_{i-1}\right)^{s_{i}+3}-\left(1-\lambda_{i}\right)^{s_{i}+3}\right]} \quad(i=2,3, \ldots, m) \\
P_{i}=\frac{0.5}{s_{i}+1} \quad(i=1)
\end{gathered}
$$

where

$$
s_{i}=n_{i}+\cdots+n_{m}, \lambda_{i}=\frac{P_{i-1} t_{i}}{t_{i-1}}
$$

After the determination of the probability of tree initiation $P_{i}$ at time $t_{\mathrm{i}}$, the two characteristic parameters in Equation (2) can be estimated as shown in Table 5. The correlation coefficient of each data set is 0.99 , testifying that the test data conforms to a 2-parameter Weibull distribution [18].

Table 5. Weibull parameters of tree initiation time data.

\begin{tabular}{cccc}
\hline \multirow{2}{*}{$\begin{array}{c}\text { Temperature } \\
\left({ }^{\circ} \mathrm{C}\right)\end{array}$} & $\begin{array}{c}\text { Scale parameter } \\
\text { (day) }\end{array}$ & $\begin{array}{c}\text { Shape } \\
\text { parameter }\end{array}$ & $\begin{array}{c}\text { Correlation } \\
\text { coefficient }\end{array}$ \\
\cline { 2 - 4 } & 223.6 & 0.567 & 0.99 \\
$\mathrm{RT}$ & 216.1 & 0.572 & 0.99 \\
\hline
\end{tabular}

According to the statistical results in Table 5, the shape parameters under the two conditions are close and both less than 1.0. This indicates that the DC XLPE insulation is prone to failures in the early stage of cable service because of the quality problems in material and manufacturing, or human factors in installation and operation. After that, its reliability will rise and it can run reliably for a rather long time [21]. This is consistent with the results of scale parameters, which is nearly 224 days at RT or 216 days at $90{ }^{\circ} \mathrm{C}$. Under similar conditions, the tree initiation voltage under constant DC may be more than 10 times higher than that under $\mathrm{AC}$ [22].

Regardless of the accuracy of time data in Table 5, it is certain that the long-time application of a HV DC constant voltage is difficult to produce an electrical tree in the XLPE insulation, even at an elevated temperature. Apart from the good endurance of DC XLPE insulation to the constant DC voltages, one possible reason is that treeing test under constant DC voltages is not an effective way to reflect the short and long-term voltage withstanding capability of the DC insulation.

Grzybowski measured AC and DC average breakdown strengths of $5 \mathrm{kV}$ XLPE cables, both sound ones and imperfect 
ones with artificial holes or embedded needles. The data are listed in Table 6 [23]. It can be seen that for all three cable types, the ratio of DC strength to AC is always higher than 3.5. For the cable with embedded needles, the AC strength is the lowest, in line with the widely agreed view that conductive tips and protrusions are the most dangerous defects in the cable insulation. However, the DC breakdown strength is only $1 / 3$ lower than that of the sound cable, and it is much higher than that of the cable with an artificial hole. The strength ratio of $\mathrm{DC}$ to $\mathrm{AC}$ is 7.3, almost 2 times as large as the other two.

Table 6. AC and DC breakdown strength of $5 \mathrm{kV}$ XLPE cable [23].

\begin{tabular}{cccc}
\hline Cable type & $A C(\mathrm{kV})$ & $D C(\mathrm{kV})$ & Ratio of DC to $A C$ \\
\hline Sound cable & 68.0 & 260.0 & 3.8 \\
Hole inside & 26.2 & 92.0 & 3.5 \\
Needle inside & 23.7 & 172.0 & 7.3 \\
\hline
\end{tabular}

Therefore, although treeing test under a constant voltage is an effective way to investigate the short and long-term electrical aging properties of AC insulating materials [24], this method is not applicable to reflect the voltage withstanding capability of DC insulation due to the influence of space charges under DC voltages whose effect will become even stronger in a pin-plane electrode system. That may be why most recent researches about DC insulation are performed under grounded DC voltage, polarity reversal voltage or superimposed impulse voltage, and abrupt grounding is recommended as a quality control method for HVDC extruded cables $[8,11,25]$.

\subsection{EFFECT OF PRESTRESS VOLTAGES ON THE TREE INITIATION}

It is found that both a $35 \mathrm{kV}$ lightning impulse and a $35 \mathrm{kV}$ DC prestress followed by an impulse voltage will cause tree initiation in AC XLPE samples with a percentage of $50 \%$ [13]. Although the test samples are different, the structure and parameters of the needle-plane electrode system are the same. So, it is reasonable to believe that $35 \mathrm{kV}$ is the voltage threshold at which sufficient amount of charges will be injected from the needle electrode to cause tree initiation under the test condition of this paper. In the impulse related experiments, $50 \%$ tree initiation rate may be the result of the dispersivity of the impulse voltage. Under grounded DC voltage, $35 \mathrm{kV}$ will lead to $100 \%$ tree initiation.

From the treeing tests under grounded DC voltages, superimposed impulse voltages or impulses after DC prestress, it was testified that charges could be injected into PMMA, PE or XLPE samples from the needle electrode, and the quick release of these charges resulted in the tree initiation $[3,6,7$, $13,14,16]$. Fukuzawa researched the charge penetration depth from the needle electrode into the LDPE samples by thermally stimulated current technique, and found that the tree length was approximately equal to the charge penetration depth [26]. In the treeing test under grounded DC voltage, as shown in Section 3.2, not only the tree initiation rate but also the average tree length increase with the increase of DC prestress voltage, which indicates that both the amount and penetration depth of charges increase with the DC prestress voltage [16].

\subsection{EFFECT OF GROUNDING RESISTOR ON THE TREE INITIATION}

When a glass enamel film resistor is connected in series with the grounding wire, it can moderate the rapid energy release from the sample caused by the sudden grounding of the needle electrode, which can be observed from trees with thinner and lighter-colored branches, as shown in Figure 6. Along with the increase of resistance, the rate of energy release decreases, the damage caused by grounding impact alleviates, and as the result, the tree initiation rate declines.

According to the dielectric theory, an insulation bulk can be simulated by a resistance in series with a capacitance. As shown in Figure 9, $R_{0}$ and $C_{0}$ are the equivalent resistance and capacitance of the XLPE dielectric between the needle and plane electrode. As shown in Figure 9a, during the charging process, a DC source which outputs a voltage of $U_{\mathrm{S}}$ is connected with the sample. After $10 \mathrm{~min}$, the DC source is disconnected and a grounding resistor $R_{\mathrm{d}}$ is introduced to discharge the sample, as shown in Figure $9 \mathrm{~b}$. At the end of the charging process, a voltage of $U_{0}$ is thought to be built up across the capacitance $C_{0}$. In theory, $U_{0}$ is smaller than $U_{\mathrm{S}}$.

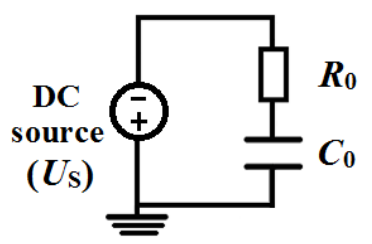

(a)

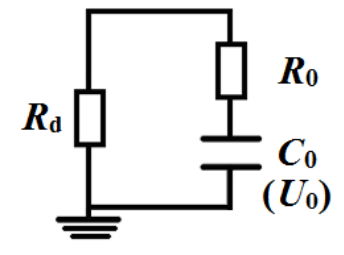

(b)
Figure 9. Equivalent circuits used for the analysis of tree initiation in XLPE samples: (a) the charging process by the application of a DC source, and (b) the dischaging process through a grounding reistor.

According to Figure 9b, during the discharging progress, the voltage across the capacitance can be calculated by:

$$
U_{\mathrm{C}}(t)=U_{0} \exp (-t / \tau), \tau=\left(R_{0}+R_{\mathrm{d}}\right) \times C_{0}
$$

Thus, the current flowing through the test sample can be determined by Equation (4):

$$
i(t)=C_{0} \frac{d U_{\mathrm{C}}(t)}{d t}=\frac{U_{0}}{R_{0}+R_{\mathrm{d}}} \exp \left[-\frac{t}{\left(R_{0}+R_{\mathrm{d}}\right) \times C_{0}}\right]
$$

It can be seen from Equation (4) that with the increase of the grounding resistance, not only the initial value of discharge current becomes smaller, but also the rate of change slows down. These two factors make the impact of grounding smaller and the energy release slower, which effectively reduce the damage of samples caused by grounding of the needle electrode.

Because of the capacitive effect of the cable insulation, any DC cable system needs to be fully discharged after it is taken off from operation or $\mathrm{HV}$ test, so as to avoid unexpected damages to the staff or to the cable itself. The direct grounding of such cables is not feasible although the discharge rate is the fastest, because this will cause serious damage to the cable insulation, which has been confirmed by the experimental results in Section 3.2. The application of a grounding resistor with a large resistance can slow down the discharge rate, but in 
the practical engineering, the discharge process should not last too long, no more than $24 \mathrm{~h}$ for example. Therefore, a properly designed discharge device would be necessary to meet the requirements both in safety and engineering. After the electrical treeing test on XLPE insulation samples in this paper, some discharge experiments will be carried out on actual cables in the following.

\subsection{EFFECT OF TEMPERATURE ON THE TREE INITIATION}

In the $\mathrm{AC}$ treeing test on XLPE cable insulation samples, Chen found that from 50 to $90{ }^{\circ} \mathrm{C}$, the increase of test temperature reduced the time for tree initiation, whereas the tree growth time was less affected [14]. Similar patterns can be found in the tree initiation tests under grounded DC voltage.

As shown in Table 4, under the same condition, the tree initiation rate increases when the temperature goes up. For example, when the resistance of glass enamel film resistor is $10 \mathrm{k} \Omega$, the tree initiation rate is $50 \%$ at $25{ }^{\circ} \mathrm{C}, 70 \%$ at $50{ }^{\circ} \mathrm{C}$, and $100 \%$ at $70{ }^{\circ} \mathrm{C}$ respectively. This indicates that an elevated temperature makes it easier for the trees to be triggered in XLPE samples. As for the shape of trees, the influence of temperature is a little more complicated. At an elevated temperature, the trees will grow faster, not only towards the opposite electrode, but also in other directions, even perpendicular to the electric field. Besides, the tree branches will become more densely distributed.

In a research about electric field in polymeric cables due to space charge accumulation, Choo found that at higher temperatures, the amount of injected charges was expected to increase because the relative injection barrier was reduced. Besides, the charges tended to have a higher mobility and the neutralization of space charges occurred faster [27]. This conclusion is consistent with that of Lan. She found from 30 to $90{ }^{\circ} \mathrm{C}$, the threshold field for space charge accumulation apparently decreased with the temperature, probably associated with acceleration of charge injection and ionic dissociation, and the apparent mobility of charges showed an exponential dependence on temperature, which indicated the enhancement of charge detrapping and transfer rate at higher temperatures [28].

So, a higher temperature will reduce the charge injection barrier, which makes more charges injected into the sample. Because of the enhanced charge mobility, expanded sample volume and increased material conductivity at an elevated temperature, these charges will diffuse away from the needle tip and reach a stable distribution more easily. If there is no external stimulus, these space charges will alleviate the concentrated field near the needle tip and hinder the tree initiation in the sample. That is why an electrical tree will not be initiated under a constant DC voltage of $-60 \mathrm{kV}$ until 224 days at RT or 216 days at $90{ }^{\circ} \mathrm{C}$, as deduced in Section 4.1. The increase of temperature has only a small impact on the tree initiation time under constant DC voltage, much less than AC trees. Undoubtedly, because the accuracy of the Bayes statistical method relies on the amount of data, more data are still needed to validate this conclusion.
The space charges widely distributed in the sample are not only the source of electric field distortion, but also the cause of electrical-mechanical energy accumulation around them. Once an adequate stimulus is applied, for example, the sudden grounding of the needle electrode, the charges will be detrapped and the electrical-mechanical energy will be released quickly. This energy can break the polymer bonds and trigger an electrical tree. Under an elevated temperature, the detrapping ability of space charges is enhanced, which causes the increase of the tree initiation rate. Besides, the increased charge amount and their enlarged distribution in the sample, as well as their higher mobility not only make the branches of grounded trees longer and denser, but also cause the branches to grow in more varied directions.

To sum up, a very long life of XLPE insulated DC cable under stable DC voltage could be expected. However, any changes in operation conditions will have a fatal impact on the reliability of cable system, such as the polarity reversal, ground failure and switching impulse, and the elevated temperature will aggravate the extent of damage. Therefore, special attentions should be paid to the performance test technique, as well as operation and maintenance strategy of the DC cable systems.

\section{CONCLUSIONS}

Conclusions are obtained as follows:

(1) After the application of a constant DC voltage of $-60 \mathrm{kV}$ for 12 days at RT or 20 days at $90{ }^{\circ} \mathrm{C}$, no trees have been initiated in the DC XLPE samples. Bayes statistical method is used to process the zero-failure data, and it is estimated to take 224 days at RT or 216 days at $90{ }^{\circ} \mathrm{C}$ for a tree to be initiated with a probability of $63.2 \%$. This indicates the excellent withstanding capability of the DC XLPE insulation to a constant DC voltage, even under an elevated temperature.

(2) Under the same condition as the constant DC tree test, grounded DC trees can be initiated under $-15 \mathrm{kV}$ prestress, and $-35 \mathrm{kV}$ prestress leads to a tree initiation rate of $100 \%$. Both the tree initiation rate and average tree length increase with the increase of DC prestress, and the relation between tree length and DC prestress can be fitted by a power function. The grounded DC trees are branch trees with dark-colored channels.

(3) The use of a grounding resistor can remarkably reduce the damage of the XLPE sample caused by the grounding impact. With the increase of grounding resistance, tree branches become thinner and lighter-colored, and tree initiation rate declines.

(4) Although the increase of temperature does not play a big role in the tree initiation time under constant DC voltage, it will promote tree initiation under grounded DC conditions. The tree branches become longer and denser, and grow in more varied directions. This may be the result of the decreased injection barrier, increased mobility and enhanced detrapping rate for the space charges under an elevated temperature. 


\section{ACKNOWLEDGEMENT}

This work is supported by a grant from the National Natural Science Foundation of China under Project No. 51777156 and the National Key Research and Development Program of China under contract 2016YFB0900703.

The authors would like to acknowledge Yang Xiao, for her efforts in the electrical tree tests.

\section{REFERENCES}

[1] Working Group B1.40, "Offshore generation cable connections," CIGRE TB 610, 2015.

[2] H. Ghorbani, M. Jeroense, C.-O. Olsson, and M. Saltzer, "HVDC cable systems - highlighting extruded technology," IEEE Trans. on Power Del. vol. 29, no. 1, pp. 414-421, 2014.

[3] M. Fujii, K. Arii and K. Yoshino, "Fractal character of DC trees in PMMA,” IEEE Trans. Dielectr. Electr. Insul., vol. 26, no. 6, pp. 1159$1162,1991$.

[4] Y.X. Zhang, Y.X. Zhou, M. Chen, L. Zhang, X. Zhang and Y.C. Sha, "Electrical tree initiation in silicone rubber under DC and polarity reversal voltages," J. of Electrostatics, vol. 88, pp. 207-213, 2017.

[5] H. Kawamura and M. Nawata, "DC electrical treeing phenomena and space charge," IEEE Trans. Dielectr. Electr. Insul., vol. 5, no. 5, pp. 741-747, 1998.

[6] F. Noto, N. Yoshimura, and T. Ohta, "Tree initiation in polyethylene by application of DC and impulse voltage," IEEE Trans. Electr. Insul., vol. 12,nNo. 1, pp. 26-30, 1977.

[7] I. Kitani and K. Arii, "DC tree associated with space charge in PMMA", IEEE Trans. Electr. Insul., Vol. EI-22, No. 3, pp. 303-307, 1987.

[8] Y. Sekii, H. Kawanami, M. Saito, K. Sugi, and I. Komatsu, "DC tree and grounded DC tree in XLPE," Annu. Rep. Conf. Electr. Insul. Dielectr. Phenom., 2005, pp. 523-526.

[9] I. Iddrissu, H.L. Zheng and S. M Rowland, "DC electrical tree growth in epoxy resin and the influence of the size of inceptive AC trees," IEEE Trans. Dielectr. Electr. Insul., vol. 24,nNo. 3, pp. 1965-1972, 2017.

[10] Y. Liu and X.L. Cao, "Electrical tree growth characteristics in XLPE cable insulation under DC voltage conditions," IEEE Trans. Dielectr. Electr. Insul., vol. 22, no. 6, pp. 3676-3684, 2015.

[11] M. Selsjord and E. Ildstad, "Electrical treeing caused by rapid DCvoltage grounding of XLPE cable insulation," IEEE Int. Symp. Electr. Insul, 2006, pp. 502-505.

[12] Y.N. Wang, G.D. Li, J.D. Wu and Y. Yin, "Effect of temperature on space charge detrapping and periodic grounded DC tree in cross-linked polyethylene," IEEE Trans. Dielectr. Electr. Insul., vol. 23, no. 6, pp. 3704-3711, 2016.

[13] Y. LIU and X.L. CAO, "Electrical tree initiation in XLPE cable insulation by application of DC and impulse voltage," IEEE Trans. Dielectr. Electr. Insul., vol. 20, no. 5, pp. 1691-1698, 2013.

[14] X.R. Chen, Y. Xu, X.L. Cao and S. M. Gubanski, "Electrical treeing behavior at high temperature in XLPE cable insulation samples," IEEE Trans. Dielectr. Electr. Insul., vol. 22, no. 5, pp. 2841-2851, 2015.

[15] Y. Tananka, "Evaluation of insulating materials for HVDC transmission cable using space charge measurement," CIGRE AORC technical meeting, SC B1-1096, pp. 1-5, 2014.

[16] M. Ieda and M. Nawata, "DC treeing breakdown associated with space charge formation in polyethylene," IEEE Trans. Electr. Insul., vol. EI-12, no. 1, pp: 19-25, 1977.

[17] Y. Liu, Y. Xiao, Y. Su, X. Chen, C. Zhang and W.P. Li, "Electrical treeing test of DC cable XLPE insulation under DC voltage and high temperature," IEEE 1st Int. Conf. Dielectr. (ICD), 2016, pp. 752-755.

[18] R. Ross, "Graphical methods for plotting and evaluating Weibull distributed data," IEEE Int. Conf. Properties Applications Dielectr. Materials (ICPADM), 1994, vol. 1, pp. 250-253.

[19] B. Efron, "Bayes' Theorem in the 21st Century," Science, vol. 340, pp. 1177-1178, 2013.

[20] Liu Hai-tao and Zhang Zhi-hua, "Bayesian reliability analysis of Weibull zero failure data," Systems Engineering - Theory \& Practice, vol. 28, no. 11 , pp. 103-108, 2008.(in Chinese)

[21] Z. Ding and S.H. Huang, "Establishment of reliability life model based on Weibull distribution," Electronic Measurement Technology, vol. 30, no. 3, pp. 34-36, 2007. 9in Chinese)

[22] Y. Liu and X.L. Cao, "A novel method for the insulation thickness design of HV XLPE cable based on electrical treeing tests," IEEE Trans. Dielectr. Electr. Insul., vol. 21, no. 4, pp. 1540-1546, 2014.

[23] S. Grzybowski and J. Fan, "Electrical breakdown characteristics of the XLPE cables under AC, DC and pulsating voltages," IEEE $5^{\text {th }}$ Int. Conf. Properties and Applications of Dielectric Materials, (ICPADM), 1997, Part 1, pp. 389-393.

[24] Standard test method for evaluation of resistance to electrical breakdown by treeing in solid dielectric materials using diverging fields, ASTM Std. D3756, 1997.

[25] M. Frank, I. Erling, H. Rolf, J. Marc, S. Bjørn, and E. L. Jan, "Evaluation of abrupt grounding as quality control method for HVDC extruded cables," Annu. Rep. Conf. Electr. Insul. Dielecr. Phenom., 2008, pp. 41-44.

[26] M. Fukuzawa and M. Iwamoto, "Study of the relationship between space charge field and electrical treeing in low density polyethylene under a needle-plane electrode system," Jap. J. Appl. Phys., vol. 37, no.7, pp. 4016-4020, 1998.

[27] W. Choo, G. Chen and S. G. Swingler, "Electric field in polymeric cable due to space charge accumulation under DC and temperature gradient," IEEE Trans. Dielectr. Electr. Insul., vol. 18, no. 2, pp. 596-606, 2011.

[28] L. Lan, J.D. Wu, Y. Yin, X.G. Li, and Z. Li, "Effect of temperature on space charge trapping and conduction in cross-linked polyethylene," IEEE Trans. Dielectr. Electr. Insul., vol. 21, no. 4, pp. 1784-1791, 2014.

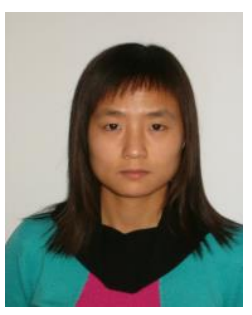

Ying Liu (M'08) was born in Sichuan, China in 1976. She received the B.Eng., M.Eng., and Dr. Eng. degrees from Xi'an Jiaotong University, Xi'an, China in 1999, 2002 and 2006, respectively. She is currently an associate professor in the Department of Electrical Engineering of Xi'an Jiaotong University. She is engaged in the design of insulation structures and measuring techniques of electrical insulation. She is a member of CIGRE B1 TAG.

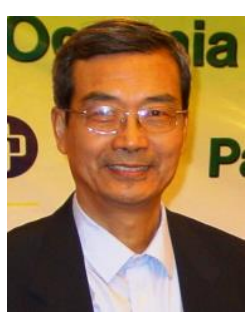

Xiaolong Cao (SM'98) was born in Shaanxi, China, 1945. He received the Ph.D degree from Xi'an Jiaotong University in 1986. He is a Professor in the Department of electrical engineering of Xi'an Jiaotong University. His research interests include dielectric materials and electrical cable technology. $\mathrm{He}$ is a senior member of IEEE D. and E.I. Society, and a member of CIGRE SC as well.

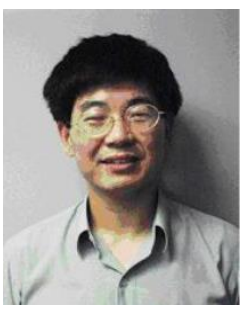

George Chen (SM'11) was born in China in 1961. He received the BEng (1983) and MSc (1986) degrees in electrical engineering from Xi'an Jiaotong University, China. After he obtained the Ph.D. degree (1990) from the University of Strathclyde, UK, on the work of permanent changes in electrical properties of irradiated low-density polyethylene, he joined the University of Southampton as postdoctoral research fellow and became a senior research fellow subsequently. In 1997 he was appointed as a research lecturer and promoted to a Reader in 2002. He is now the professor of high voltage engineering at the University of Southampton and a visiting professor of Xi'an Jiaotong University. Over the years, he has developed a wide range of interests in high voltage engineering and electrical properties of materials and published over 300 papers. He is active in the HVDC systems and involved with technical working groups in both IEEE and CIGRE. 